\title{
Multi-objective Optimization of Construction Project Based on Improved Ant Colony Algorithm
}

\author{
Yancang LI, Shuren WANG, Yongsheng HE
}

\begin{abstract}
It is the key and difficult problem for the current project management to consider the multi-objective optimization of the four elements, such as quality, duration cost and safety. To improve the accuracy and efficiency of project management during the engineering construction, considering the advantages and disadvantages of the traditional quality-cost-time model, the four elements were regarded as a system, and a multi-objective optimization model was established. The improved ant colony algorithm was used to carry out multi-objectives of construction projects to overcome the premature defect of the traditional method. The optimal plan of the project was found and the overall efficiency of the construction project management was improved. Results show the optimized ant colony algorithm can avoid the low efficiency of the optimal solution search and the shortcoming of the initial pheromone. The engineering practice proves that the enhanced algorithm has solved the problem of the multiobjective optimization of quality, duration, cost and safety. The obtained conclusions are of significant reference value to direct the similar engineering practice.
\end{abstract}

Keywords: ant colony algorithm; fitness function; model; multi-objective optimization; project management

\section{INTRODUCTION}

As we all know, the four indicators, such as quality, duration, cost and safety management are of great significance to maximize the interests of enterprises. These four critical indicators of construction projects are highly correlated and contradictory, but the engineering projects must meet these conflicting project objectives at the same time [1-4].

The traditional approach to project management was to put quality, schedule, and cost together. For example, Khaled \& Amr applied the balance model of program, cost, and quality to the actual construction project and evaluated the reliability of the model [5]. Dho \& Khaled proposed a multi-objective optimization model that could measure and reduce unnecessary resource changes [6]. Gholamreza \& Shiva introduced a fuzzy simple weighted random quality evaluation system and a decision-making framework [7]. At the same time, they found the optimal utilization rate of resources considering time, cost and quality.

As an important part of construction management, safety management has an important impact on reducing sudden accidents in construction, ensuring smooth construction and improving economic benefits. So it is important to establish a multi-objective comprehensive optimization model to use the heuristic simulation algorithms, combining the four indicators, such as quality, duration, cost and safety management.

\section{STATE OF THE ART}

In the past years, many scholars had focused on the optimization methods for the construction project management. Ayman et al. conducted the statistical analysis on the cost and duration by using a real historical data [8]. Yang et al. defined the task duration with fuzzy numbers, set an acceptable risk level, established membership function, and finally converted the uncertain term being expressed by fuzzy numbers into common sets $[9,10]$. Mckim et al. believed that the goal control of project management included progress, cost, quality, resources, safety, environment factors and other objectives [11]. Zhang et al. used the time-cost-quality of the contract to evaluate the feasible solution of decision-making [12]. Soares et al. studied the cost-effective risk management system for chemical processes based on optimal control [13]. Koo et al. studied the multi-objective optimization model to solve construction time-cost trade-off problem [14]. Monghasemi et al. proposed a multi-criteria decision model for optimizing time-cost-quality trade-off problems in construction projects [15]. But the safety factor of the project management is rarely reported in their studies.

Recently, lots of achievements have been made in both project management optimization and engineering practice. Moumen et al. combined quality, safety, and environment into an integrated management system [16]. Islam et al. assessed the cost overrun risks of a power plant project based on the expert system [17]. Farahnaz \& Kaveh studied the stochastic time-cost-quality trade-off project scheduling problem considering multiple-execution modes [18]. Zalmai et al. applied the time-cost optimization to the construction project by using harmony search algorithm [19]. Ahn et al. researched the integrated risk management method for multiple aerospace projects by using a single index expression [20]. Togan \& Eirgash conducted the time-cost trade-off optimization of the construction projects by using teaching learning [21]. Adolfoet al. invested the experiences challenges pertaining to the quality of the practice environment [22-23]. Howerver, the existing quality-cost-time model must be further studied regarding the safety factor.

From the results mentioned above, the traditional approach did not consider the inclusion of safety in the scope of management. As an essential part of project management, safety management has a significant impact on reducing sudden accidents in construction, ensuring smooth construction and improving economic efficiency. Therefore, the four key factors, such as the quality, duration, cost and safety management were considered together to increase the overall value of the project.

To achieve the comprehensive optimization, a multiobjective optimization model was established by using the improved ant colony algorithm. The optimized ant colony algorithm could avoid the low efficiency of the optimal solution search and the shortcoming of the initial pheromone. The optimal plan of the project was found and 
the overall efficiency of the construction project management would be improved.

The remainder of this study was organized as follows. In Section 3, the research methods were introduced. In Section 4, Performance verification of the improved ant colony optimization algorithm was analyzed and discussed. Finally, the main conclusions were given in Section 5.

\section{METHODOLOGY}

\subsection{Duration-cost Optimization Model}

With the development of modern economic environment and management science, the cost control has become more and more critical. The curve between the direct cost and indirect cost is not consistent with the duration of the engineering project, the study of the direct and indirect cost should be separated.

In this study, the total cost of the project was divided into direct cost, indirect cost, and engineering tardiness compensation. From the view of the direct cost and schedule, any process in the project will have a variety of implementation modes, and the construction party will choose the most reflective mode according to the site, the direct cost and the working duration are non-linear and display a quadratic curve. Therefore, this study assumed that the direct cost-work duration function is a quadratic function which meets the shape of the quadratic curve. The indirect cost included personnel wages, transportation benefits, etc., which were not directly used in the project itself. With the duration being shortened, the corresponding costs were also reduced. Therefore, to simplify the calculation, it was assumed that the indirect cost was linearly related to the duration. The project delay compensation is the reward or penalty cost when the project leads or lags behind the target period. In the actual project, the union is rewarded in advance according to the contract requirements; similarly, the plan that delays the completion of the duration will also be punished by the lost work. Therefore, considering the cost-time model of the reward and punishment system will be closer to the actual project.

In summary, the cost-work period was a power function, and the cost increase coefficient $\alpha_{i}$ was introduced to subdivide the construction situation under different working conditions, which was closer to the actual project. The objective function of the duration-cost can be expressed as:

$$
\begin{aligned}
& T=\sum_{i=1}^{n} t_{i} \\
& C=\sum_{i=1}^{n}\left[C_{i n}+\alpha_{i}\left(t_{i}-t_{i n}\right)^{2}\right]+\beta\left(T_{b}-T_{c}\right)+\gamma T_{c} \\
& \text { s.t. } \quad t_{i s}<<t_{i}<<t_{i l}
\end{aligned}
$$

where $C_{i n}$ is the direct cost of $i$ working normal duration, $\alpha_{i}$ is the cost increase factor, $\beta$ is the reward penalty coefficient, $\gamma$ is the indirect cost factor, $T_{b}$ is the total project budget, $T_{c}$ is the actual total duration, $t_{i}$ is the actual duration of $i$ work, $t_{i n}$ indicates the normal duration of $i$ work, $t_{i s}$ indicates the shortest duration of $i$ work, and $t_{i l}$ indicates the longest duration of $i$ work.

\subsection{Duration-quality Optimization Model}

The project activity is determined by each sub-project. Only by guaranteeing the quality of each sub-project, the overall quality can be guaranteed. In the process of optimizing the balance of engineering management, generally the quality level of engineering activities is based on the continuous value of 1-0, indicating the strictness of the quality requirements of an activity. The closer to 1 , the higher the strictness of the activity quality requirements, and the closer to 0 indicates the rigor of the activity quality requirement is lower. A project is necessary to consider the importance of different activities for the entire project, so for the activities of the project to allocate different weight coefficients. If the quality of some activities decreases or improves will have a greater impact on the project, then these activities will be allocated a larger weight value, whereas activities will be allocated a smaller weight value. Thus, the total quality level of the project can be obtained through weighted summation of the quality of each project activity. The objective function of the duration-quality can be expressed as:

$$
\begin{aligned}
& Q=\sum_{i=1}^{n} \varphi_{i} q_{i} \\
& \text { s.t. } \quad \varphi_{i}>0, \quad \sum_{i=1}^{n} \varphi_{i}=1 \\
& 0<<q_{i} \quad<<1
\end{aligned}
$$

where $Q$ is the total quality of the project, $\varphi_{i}$ is the quality weight coefficient of activity $i$ in the whole project, and $q_{i}$ is the quantified value of the quality level of activity $i$.

\subsection{Duration-safety Level Model}

The safety cost is derived from guaranteed safety costs and lost safety costs [24]. Guaranteed safety cost refers to the cost of increasing the safety factor of the project and reducing the incidence of accidents, including the cost of safety training for construction workers before construction, the cost of purchasing safety facilities, etc. The loss safety cost refers to all the costs caused by accidents. Assuming $\mu$ is the safety cost rate of the project ( safety cost rate $=$ safety cost/total cost), the safety cost of activity $i$ is recorded as $C_{i s}$, and $C_{i s}=\mu_{i} c_{i}$. If the probability of an activity accident is $p_{i}$, the safety level index of active $i$ is as follows:

$S_{i}=1-p_{i}=1-p_{0 i}\left(1-\Delta p_{i}\right)$

$\Delta p_{i}=\Delta p_{i l}+\left(\Delta p_{i h}-\Delta p_{i l}\right) \frac{C_{i s}-C_{i s}^{\prime}}{C_{i s}^{\prime \prime}-C_{i s}^{\prime}}$

$S=\sum_{i=1}^{n} S_{i}=\sum_{i=1}^{n}\left[1-p_{0 i}\left(1-\Delta p_{i}\right)\right]$

Where: $S_{i}$ is the safety level index of activity $i$; $p_{0 i}$ is the initial probability of safety accidents in activity $\mu$ (different values of $\mu$ correspond to different $p_{0 i}$ ); the safety cost rate of the project is $\mu ; \Delta p_{i}$ is the decreasing proportion of safety accidents probability when safety costs are put into activity 
$i ; \Delta p_{i l}$ is the lowest decreasing proportion of the probability of safety accidents after putting safety costs into activity $i$; $\Delta p_{i h}$ is the highest decreasing proportion of the probability of safety accidents after putting safety costs into activity $i$; $C_{i s}^{\prime}$ is the minimum guaranteed security cost of the activity $i$, and $C_{i s}^{\prime \prime}$ is the highest guaranteed security cost of the activity $i$.

\subsection{Fitness Function}

As seen from the following equations, Eq. (14) is the fitness function, and the smaller $D$ is, the better the overall goal is.

$$
\begin{aligned}
& D_{T}=\frac{T_{\max }-T}{T_{\max }-T_{\min }} \\
& D_{C}=\frac{C_{\max }-C}{C_{\max }-C_{\min }} \\
& D_{Q}=\frac{Q-Q_{\min }}{Q_{\max }-Q_{\min }} \\
& D_{S}=\frac{S-S_{\min }}{S_{\max }-S_{\min }} \\
& \max \left\{D=-\sqrt{D_{T} D_{C} D_{Q} D_{S}}\right\}
\end{aligned}
$$

\subsection{Duration-cost-quality-safety Equilibrium Optimization Model}

To pursue short duration, low cost, high level of quality, and high level of safety index, the multi-objective optimization model of engineering project can be established as follows (including the constraints Eqs. (5) and (6)):

$$
\begin{aligned}
& \min T=\sum_{i=1}^{n} t_{i} \\
& \left\{\min C=\sum_{i=1}^{n}\left[C_{i n} \alpha_{i}\left(t_{i}-t_{i n}\right)^{2}+\beta\left(T_{b}-T_{c}\right)+\gamma T_{c}\right.\right. \\
& \max Q=\sum_{i=1}^{n} \varphi_{i} q_{i} \\
& \max S=\sum_{i=1}^{n} S_{i}=\sum_{i=1}^{n}\left[1-p_{0 i}\left(1-\Delta p_{i}\right)\right] \\
& S_{i}=1-p_{i}=1-p_{0 i}\left(1-\Delta p_{i}\right) \\
& \Delta p_{i}=\Delta p_{i l}+\left(\Delta p_{i h}-\Delta p_{i l}\right) \frac{C_{i s}-C_{i s}^{\prime}}{C_{i s}^{\prime \prime}-C_{i s}^{\prime}}
\end{aligned}
$$

$$
\text { s.t. } \quad t_{i s}<<t<<t_{i l}
$$

\subsection{Improved Ant Colony Optimization Algorithm}

Ant colony algorithm works by accumulating and updating pheromones, i.e. positive feedback. It is a gradually convergent optimal path optimization algorithm with the ability of distribution, global and parallel convergence. However, pheromones accumulate slowly at the beginning, which leads to a long time of pheromone accumulation at the beginning of the search. When the population size is large, the initial algorithm is slow, and the search speed reaches a certain degree. All the solutions are identical, so the solution space cannot be further searched to find better solution, and the search solution is prone to premature phenomenon. Genetic algorithm has the ability of fast global search, but the feedback information in the system is not utilized, which often leads to a number of inactive redundant iterations, and the efficiency of solving exact solutions is low.

The genetic algorithm can produce a new genome combination, expecting to combine the beneficial genomes together. There are two purposes of introducing mutation into genetic algorithm. One is the local random search ability [25]. In order to prevent the block, which is closer to the optimal solution from being caused by factors. The mutation is destroyed, so the mutation probability should be smaller. Another is the population diversity, in order to prevent premature convergence, the convergence probability should be larger [26]. Genetic algorithm has the ability of balanced searching by crossover and mutation, which are both cooperative and competitive.

The crossover and mutation operators were added to avoid the premature convergence of the algorithm. Through crossover, the search ability of genetic algorithms had been greatly improved [27]. Therefore, the optimized ant colony algorithm not only exerts the advantages of genetic algorithm and ant colony algorithm in the search optimization, but also avoids the low efficiency of the optimal solution search and the shortcoming of the algorithm. It is a heuristic algorithm with better time efficiency and solution efficiency.

The initial value setting of the pheromone is to set the maximum value $\tau_{\max }$ of each path pheromone. At the beginning, a certain path pheromone is obtained by genetic algorithm, so the initial value is set to $\tau_{s}=\tau_{0}+\tau_{c}$. Among them, $\tau_{0}$ is a constant according to the size of the problem, which is equivalent to $\tau_{\max }$ in the algorithm. $\tau_{c}$ is the pheromone value of genetic algorithm solution conversion.

The pheromone updating model is that only the ant colony with relative short path can make pheromone modification and increase after all the ants have traversed all the project tasks. That is, only the shortest path length in the first $90 \%$ ant colony is used to update pheromone. The path update equations for all paths are:

$t_{i j}(t+1)=\rho t_{i j}(t)+\sum \Delta \tau_{i j}^{k}(t)$

$\sum \Delta \tau_{i j}^{k}(t)=\frac{Q_{u}}{L_{k}}$

If $0.9 \rho>>\rho_{\min }$, then $\rho=0.9 \rho$; otherwise $\rho=\rho_{\text {min }}$. Among them, $t_{i j}(t)$ is the pheromone track intensity of path $(i, j)$ at $\mathrm{t}$ time. $\Delta \tau_{i j}^{k}(t)$ is the number of pheromones of unit length tracks left by ant colony $k$ on path $(i, j), \rho$ is a pheromone retention rate, $\sigma \in(0,1) \cdot Q_{u}$ is the total amount of pheromone released by the ant through the unit journey. $L_{k}$ denotes the length of the path travel by the kth ant colony 
in this cycle, so that the infeasible solution cannot enter the solution space, thus speeding up the convergence.

This study proposes an improved optimization algorithm for the shortcomings of the standard ant colony optimization algorithm. The idea of crossover and mutation operator effectively improves the population diversity, so as to avoid the ant colony optimization algorithm falling into local optimum. Specifically, when the ant individual selects a path, the solution of the path is formed by each individual in the ant colony according to the crossover and mutation operator in the genetic algorithm. And regrouping is based on crossover probability. The randomly select several sets of solutions that are newly arranged. Under the premise that the optimal solution has been obtained, it is further judged whether there is a better solution, and the standard algorithm is prevented from falling into the local optimal solution. This improvement makes full use of the random local search ability and the advantage of maintaining the diversity of the population, so that the two algorithms form a composite optimization algorithm with complementary advantages, namely the optimization precision and optimization efficiency of the algorithm.

When the amount of pheromone left on the path is too large, the heuristic information will be buried by it, and the convergence speed is significantly reduced. Therefore, this improvement introduces a fitness function on the path pheromone calculation. By introducing the pheromone concentration on the dynamic update path of the fitness function, the optimal pheromone concentration path is selected and the path trajectory is modified. This improvement can find the optimal pheromone concentration path and improve the convergence speed. The specific steps of the improved ant colony optimization algorithm are shown in Fig. 1.

The cost-duration-quality optimization is as follows:

Step 1: Use genetic algorithm to produce a better solution and leave pheromone in this path.

Step 2: Define fitness function, population number, iteration number and parameters.

Step 3: $i=i+1$.

Step 4: Place the initial starting point of each ant in the current solution set, for each ant $k(k=1,2, \ldots, m)$, according to probability $p_{i j}^{k}$, place the vertex $j$ in the current solution set, complete a trip, generate a set of feasible solutions.

Step 5: According to the crossover probability, select a number of groups of solutions, and then group the crossover solution, if the new objective function becomes better, accept the new value, otherwise reject.

Step 6: According to the mutation probability, the mutation of the objective function becomes better, accept the new value, otherwise reject.

Step 7: Calculate the fitness function value $L_{k}(k=1,2$, $\ldots, m)$ and record the current optimal solution.

Step 8: For the path whose fitness function $L_{k}$ is less than a given value, update the pheromone according to $t_{i j}(t+1)=\rho t_{i j}(t)+\sum \Delta \tau_{i j}^{k}(t)$, and modify the trajectory strength.

Step 9: If $i$ is less than the predetermined number of iterations, turn to step 3 .
Step 10: If $i$ is more than a predetermined number of iterations and no degenerate behavior, then judge $\mid L_{k+1}-$ $L_{k} \mid<A$. If the two solutions are in a certain range, the output is the best solution at present, otherwise step 3 .

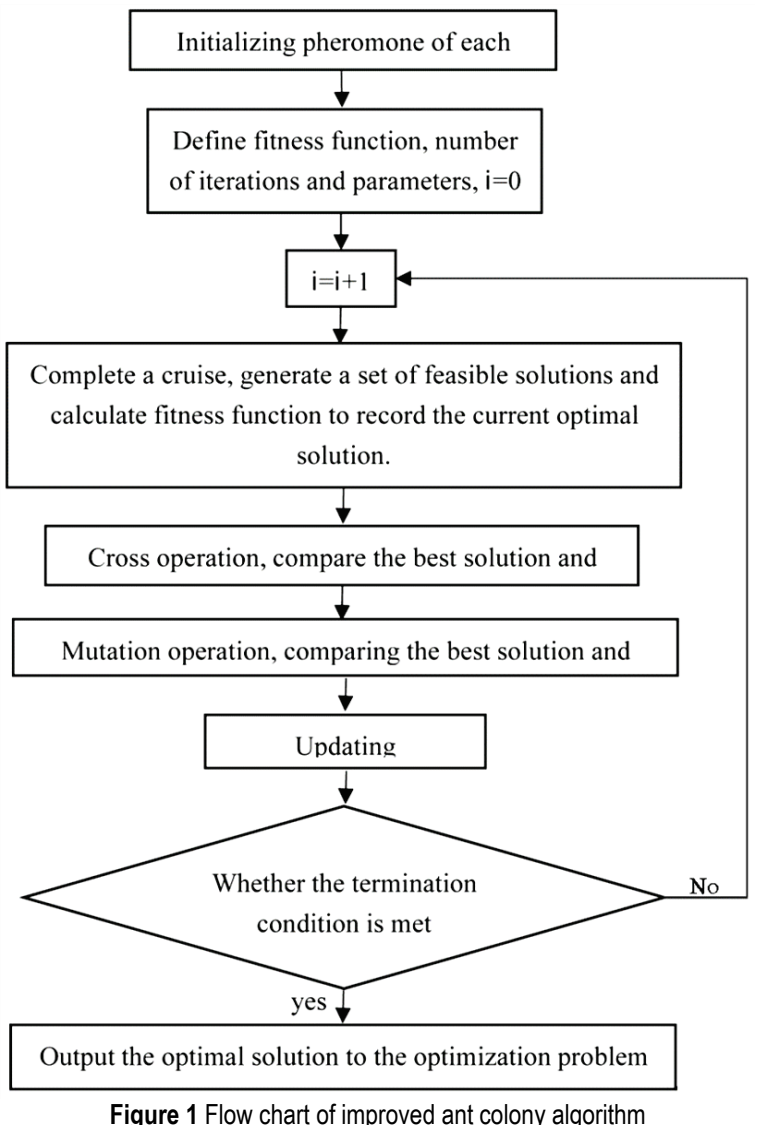

\section{RESULTS AND DISCUSSION}

\subsection{Performance Verification of Improved Ant Colony Optimization Algorithm}

To verify the improved ant colony algorithm IACO, and compare it with basic ant colony algorithm ACO, bat algorithm BA, particle swarm optimization PSO [28]. The three test functions are as follows:

(1) Sphere function:

$$
f_{1}(x)=\sum_{i=1}^{n} x_{i}^{2}
$$

(2) Griewank function:

$$
f_{2}(x)=\frac{1}{4000} \sum_{i=1}^{n} x_{i}^{2}-\prod_{i=1}^{n} \cos \frac{x_{i}}{\sqrt{i}}+1
$$

(3) Rosenbrock function:

$$
f_{3}(x)=\sum_{i=1}^{n-1}\left[100\left(x_{i+1}-x_{i}^{2}\right)^{2}+\left(x_{i}-1\right)^{2}\right]
$$

The dimensions of each function, the search interval of the variables, and the theoretical extremum are listed in Tab. 1. The higher the dimension of the function is, the 
larger the search interval of the variable and the higher the target convergence accuracy will be, as well as the higher the performance of the optimization algorithm is. What's more, the difficulty of searching for the optimal solution is relatively higher. The experimental setup of each test function was operated 20 times independently, taking the average of 20 experimental results as the final result.

\begin{tabular}{|c|c|c|c|} 
Table 1 Parameter setting of the test function \\
\begin{tabular}{|c|c|c|c|}
\hline Function & Dimension & Search interval & $\begin{array}{c}\text { Theoretical } \\
\text { extremum }\end{array}$ \\
\hline Sphere & 30 & {$[-100,100]$} & 0 \\
\hline Griewank & 30 & {$[-600,600]$} & 0 \\
\hline Rosenbrock & 30 & {$[-100,100]$} & 10 \\
\hline
\end{tabular}
\end{tabular}

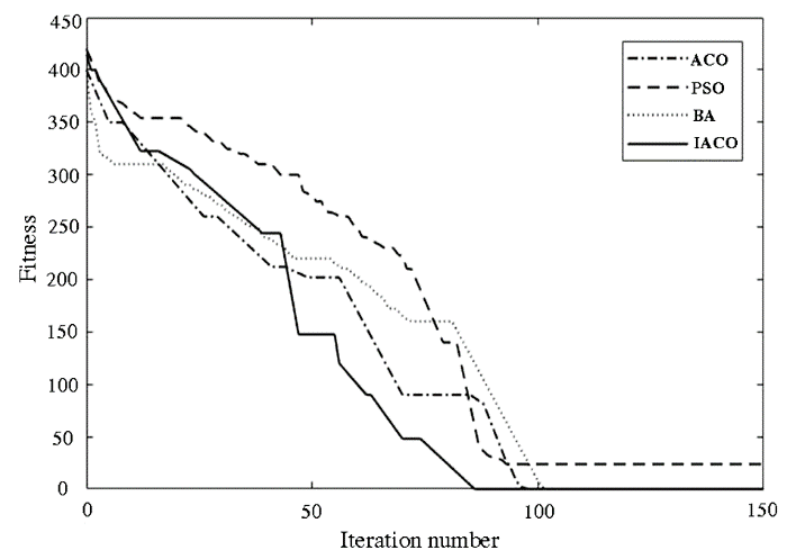

(a) Sphere function

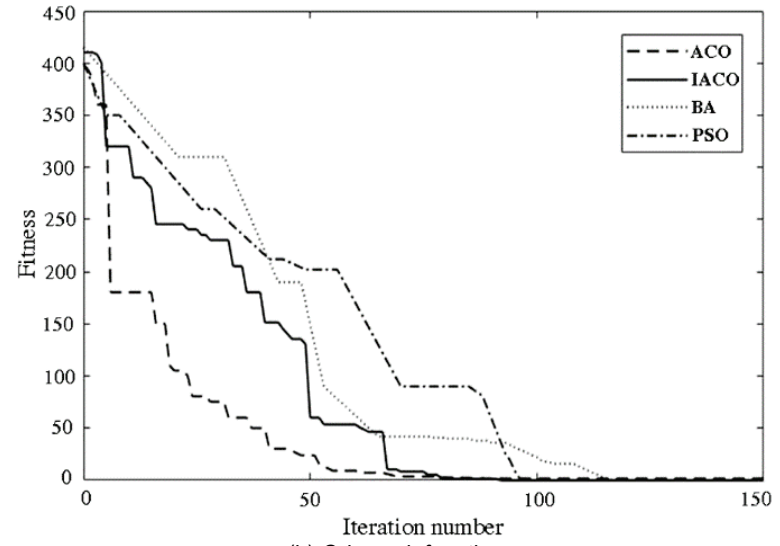

(b) Griewank function

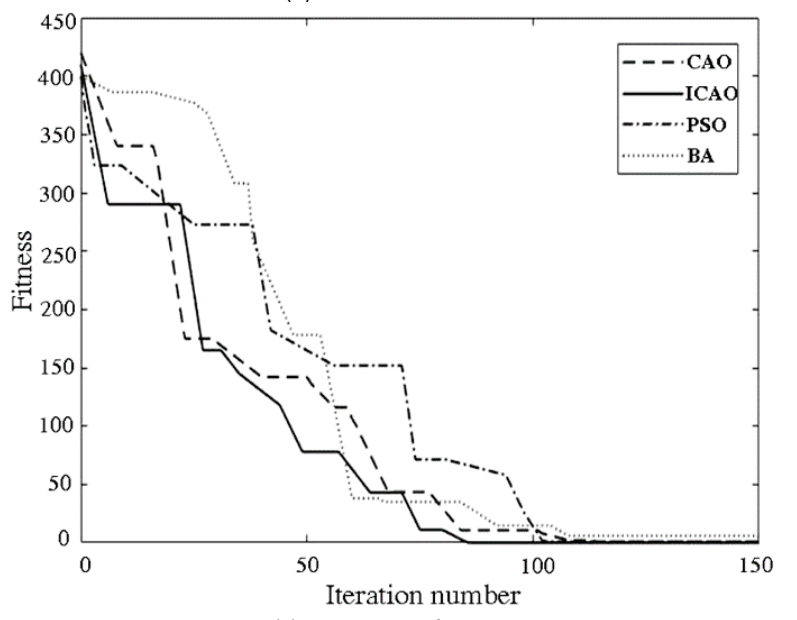

(c) Resonbrock function

Figure 2 Different function iterative graphs

Tab. 2 shows the test results for 20 experiments per test function, including the worst value (Max) of the 20 experimental results, the most excellent value (Min), average of 20 experimental results (Mean) and standard deviation (Std). Fig. 2 also shows the fitness iterative optimization curves for the three test functions.

\begin{tabular}{|c|c|c|c|c|c|}
\multicolumn{7}{c}{ Table 2 Test results of two algorithms } \\
\hline \multirow{3}{*}{ Function } & $\begin{array}{c}\text { Test } \\
\text { target }\end{array}$ & IACO & ACO & BA & PSO \\
\hline \multirow{4}{*}{ Sphere } & Max & 0 & 0.0231 & 0.0564 & 0.8650 \\
\cline { 2 - 6 } & Min & 0 & 0 & 0.0256 & 0.0090 \\
\cline { 2 - 6 } & Mean & 0 & 0.0031 & 0.5800 & 0.0092 \\
\cline { 2 - 6 } & Std & 0 & 0.0060 & 0.4000 & 0.0005 \\
\hline \multirow{5}{*}{ Griewank } & Max & 0 & 0 & 2.8000 & 0.6800 \\
\cline { 2 - 6 } & Min & 0 & 0 & 1.1000 & 0.0323 \\
\cline { 2 - 6 } & Mean & 0 & 0 & 1.6600 & 0.0440 \\
\cline { 2 - 6 } & Std & 0 & 0 & 0.5410 & 0.0410 \\
\hline & Max & 27.9717 & 28.8934 & 28.0100 & 35.1549 \\
\cline { 2 - 6 } & Min & 26.4716 & 28.3812 & 27.0001 & 33.5600 \\
\cline { 2 - 6 } & Mean & 27.1292 & 28.7452 & 28.4660 & 35.6000 \\
\cline { 2 - 6 } & Std & 0.2692 & 0.1128 & 1.7700 & 1.8000 \\
\hline
\end{tabular}

As seen in Tab. 2, for the single-peak function of Sphere and Rosenbrock, the IACO optimal, worst value, average, and standard deviation are basically better than ACO (except for the ACO's standard deviation of the function Rosenbrock test is less than IACO), And far better than PSO and BA. It can also be seen from the iteration curve that ACO cannot jump out after falling into local optimum, resulting in low convergence accuracy, and IACO can perform global search, and the convergence speed is also significantly faster than ACO. Compared with IACO and PSO and BA, IACO has faster convergence and better search ability. The multi-peak function of Griewank, IACO is easier to achieve global convergence, which is significantly better than others in several evaluation indicators, and the theoretical extremes of the function are found in 20 experiments.

\subsection{Engineering Verification Analysis}

A construction project is as follows: the project consists of 9 sub-projects, the logical relationship of each work is shown in Fig. 3. As shown in Tab. 3, the quality level of the project is required to be no less than 0.94 and the safety index is not less than 0.96 . The reward coefficient of the project $\beta$ is 10,000 yuan/day, the indirect cost coefficient $\gamma$ is 0.2 million yuan/day, and the total period $T_{b}$ of the project construction is 140 days.

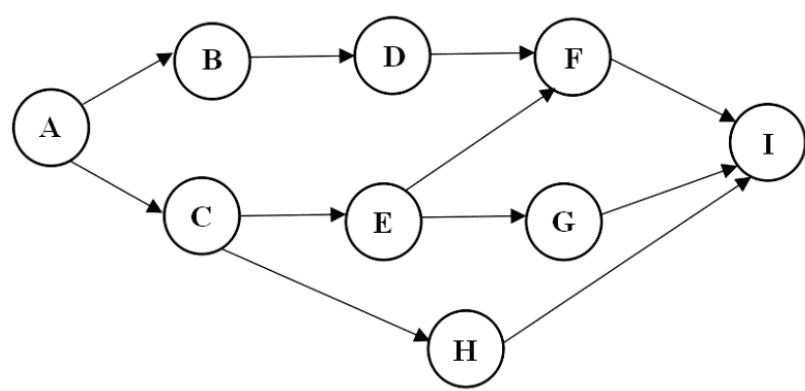

Figure 3 Logical relationship of each work

The unit of $C_{i n}, C_{i s}^{\prime}, C_{i s}^{\prime \prime}$ in the table is 10,000 yuan, and the unit of $t_{i s}, t_{i n}, t_{i l}$ is the day, which is obtained through bidding. The unit of $\alpha_{i}$ and $\varphi_{i}$ is 1 , which is obtained according to the expert score. $q_{i}, p_{0 i}, \Delta p_{i l}, \Delta p_{i h}$ consider the 
historical experience data of similar projects (assume that the quality level index of each work completed under normal duration $t_{\text {in }}$ is 1 ).

MATLAB is used to solve the above engineering examples. The relevant parameters are set to: $N_{\text {ant }}=100, \rho$ $=0.5$. Cycle times $n=200$. The crossing probability is 0.8 , the mutation probability is 0.1 . According to the above algorithm, the Pareto solution of time-cost-quality and the corresponding duration of each process are listed, as shown in Tabs. 4 and 5.

Table 3 The related parameters of activities

\begin{tabular}{|c|c|c|c|c|c|c|c|c|c|c|c|c|}
\hline Activity & $C_{\text {in }}$ & $\alpha_{i}$ & $t_{i s}$ & $t_{\text {in }}$ & $t_{i l}$ & $\varphi_{i}$ & $q_{i}$ & $p_{\text {oi }}$ & $\Delta p_{i l}$ & $\Delta p_{\text {ih }}$ & $C_{i s}^{\prime}$ & $C_{i s}^{\prime \prime}$ \\
\hline$A$ & 32.1 & 1.49 & 22 & 27 & 31 & 0.114 & 0.912 & 0.14 & 0.05 & 0.90 & 16 & 20 \\
\hline$B$ & 23.4 & 1.41 & 20 & 24 & 30 & 0.105 & 0.893 & 0.12 & 0.08 & 0.89 & 13 & 15 \\
\hline$C$ & 24.4 & 1.21 & 19 & 26 & 32 & 0.113 & 0.901 & 0.10 & 0.06 & 0.85 & 13 & 16 \\
\hline$D$ & 26.0 & 1.11 & 16 & 23 & 27 & 0.109 & 0.878 & 0.08 & 0.02 & 0.85 & 14 & 19 \\
\hline$E$ & 27.6 & 1.04 & 18 & 22 & 26 & 0.116 & 0.881 & 0.11 & 0.09 & 0.91 & 15 & 20 \\
\hline$F$ & 29.7 & 1.21 & 21 & 24 & 28 & 0.112 & 0.902 & 0.12 & 0.10 & 0.87 & 16 & 21 \\
\hline$G$ & 30.6 & 1.18 & 20 & 22 & 27 & 0.119 & 0.899 & 0.10 & 0.08 & 0.92 & 16 & 20 \\
\hline$H$ & 16.5 & 1.06 & 25 & 29 & 33 & 0.108 & 0.904 & 0.11 & 0.07 & 0.90 & 14 & 16 \\
\hline$I$ & 26.1 & 1.22 & 20 & 22 & 28 & 0.104 & 0.895 & 0.12 & 0.05 & 0.90 & 13 & 19 \\
\hline
\end{tabular}

Table 4 Part time Pareto solution of time cost quality

\begin{tabular}{|c|c|c|c|c|c|c|c|c|}
\hline $\begin{array}{c}\text { Target } \\
\text { value }\end{array}$ & $\begin{array}{c}\text { Plan } \\
1\end{array}$ & $\begin{array}{c}\text { Plan } \\
2\end{array}$ & $\begin{array}{c}\text { Plan } \\
3\end{array}$ & $\begin{array}{c}\text { Plan } \\
4\end{array}$ & $\begin{array}{c}\text { Plan } \\
5\end{array}$ & $\begin{array}{c}\text { Plan } \\
6\end{array}$ & $\begin{array}{c}\text { Plan } \\
7\end{array}$ & $\begin{array}{c}\text { Plan } \\
8\end{array}$ \\
\hline$T$ & 110 & 113 & 115 & 117 & 121 & 125 & 127 & 130 \\
\hline$C$ & 298.5 & 292.6 & 286.8 & 279.5 & 268.3 & 261.9 & 253.4 & 245.1 \\
\hline$Q$ & 0.73 & 0.82 & 0.94 & 0.96 & 1.0 & 0.98 & 0.97 & 0.97 \\
\hline$S$ & 0.89 & 0.94 & 0.96 & 0.98 & 1.0 & 1.0 & 0.98 & 0.99 \\
\hline
\end{tabular}

From Tabs. 4 and 5, the duration of each activity and the overall situation of each process can be intuitively understood in different states to better help the project manager to make decisions.

Table 5 Duration of each activity

\begin{tabular}{|c|c|c|c|c|c|c|c|c|}
\hline $\begin{array}{c}\text { Target } \\
\text { value }\end{array}$ & $\begin{array}{c}\text { Plan } \\
1\end{array}$ & $\begin{array}{c}\text { Plan } \\
2\end{array}$ & $\begin{array}{c}\text { Plan } \\
3\end{array}$ & $\begin{array}{c}\text { Plan } \\
4\end{array}$ & $\begin{array}{c}\text { Plan } \\
5\end{array}$ & $\begin{array}{c}\text { Plan } \\
6\end{array}$ & $\begin{array}{c}\text { Plan } \\
7\end{array}$ & $\begin{array}{c}\text { Plan } \\
8\end{array}$ \\
\hline$A$ & 25 & 26 & 26 & 26 & 27 & 28 & 28 & 29 \\
\hline$B$ & 22 & 23 & 22 & 23 & 24 & 24 & 26 & 26 \\
\hline$C$ & 21 & 23 & 22 & 22 & 23 & 24 & 25 & 26 \\
\hline$D$ & 19 & 21 & 23 & 23 & 23 & 23 & 24 & 24 \\
\hline$E$ & 20 & 21 & 22 & 21 & 22 & 24 & 23 & 25 \\
\hline$F$ & 23 & 22 & 22 & 23 & 24 & 23 & 24 & 25 \\
\hline$G$ & 23 & 21 & 22 & 21 & 22 & 24 & 23 & 24 \\
\hline$H$ & 27 & 24 & 26 & 25 & 27 & 26 & 27 & 28 \\
\hline$I$ & 21 & 21 & 22 & 22 & 23 & 25 & 25 & 25 \\
\hline
\end{tabular}

For multi-objective optimization problems, the comparison chart of GA, PSO, ACO, and IACO optimization process is shown in Fig. 4.

Table 6 Comparison of GA, PSO, ACO and IACO optimization results

\begin{tabular}{|c|c|c|c|c|}
\hline Algorithm & $\begin{array}{c}\text { Quality } \\
\text { optimization } \\
(\%)\end{array}$ & $\begin{array}{c}\text { Period } \\
\text { optimization } \\
(\%)\end{array}$ & $\begin{array}{c}\text { Cost } \\
\text { optimization } \\
(\%)\end{array}$ & $\begin{array}{c}\text { Safety } \\
\text { optimization } \\
(\%)\end{array}$ \\
\hline GA & 8.73 & 13.44 & 14.23 & 8.21 \\
\hline PSO & 8.94 & 12.43 & 13.48 & 8.45 \\
\hline ACO & 9.45 & 14.23 & 14.82 & 9.69 \\
\hline IACO & 11.21 & 20.85 & 15.26 & 11.32 \\
\hline
\end{tabular}

The optimization results of construction schemes are compared with those shown in Tab. 6. It can be seen that the improved ant colony algorithm is obviously superior to others in solving speed and accuracy, thus proving the feasibility and good performance.

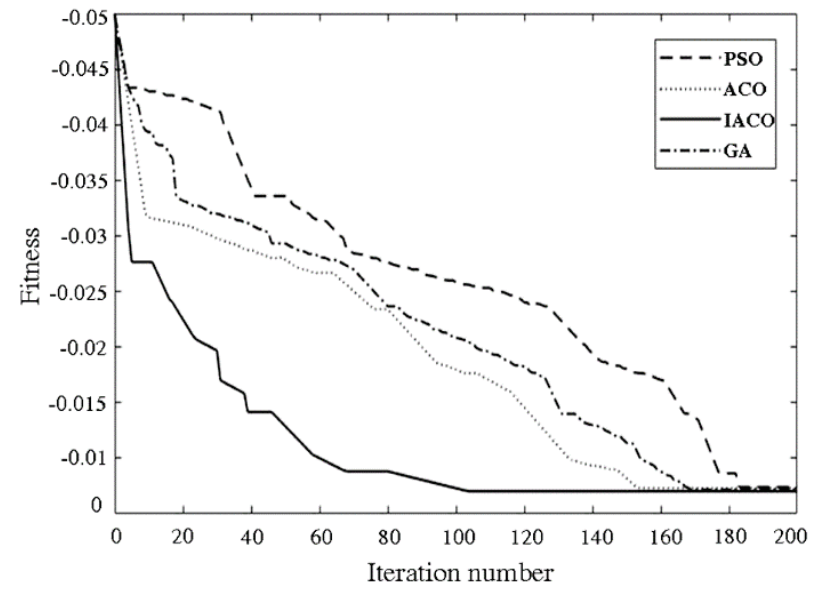

Figure $4 \mathrm{GA}$, PSO, ACO, and IACO optimized path comparison chart

\section{CONCLUSION}

Based on the analysis of traditional multi-objective optimization model, a new optimization model of quality, time limit, cost, and safety were proposed and the fitness function to consider the four factors was introduced avoiding the subjective weight analysis. The improved ant colony algorithm reduced the local optimality and improved the global search of the algorithm. The excellent ability, good results in the accuracy of the solution and the expected goal were achieved.

However, since the ant colony algorithm is still in development, there are still many aspects worthy of research in the application of construction project optimization. This study provides a new idea for engineering project management, but in the construction project management, not only quality, time limit, cost, and safety have an impact on a project, but also other factors such as environment, resources, and other objectives. Therefore, how to optimize the construction project under the premise of considering these objectives will be a principal research direction.

\section{Acknowledgements}

This study was financially supported by the National Natural Science Foundation of China (51774112; U1810203), the International Cooperation Project of Henan Science and Technology Department (182102410060), the Doctoral Fund of Henan Polytechnic University (B2015-67).

\section{REFERENCES}

[1] Jung, Y. \& Kang, S. (2007). Knowledge-based standard progress measurement for integrated cost and schedule performance control. Journal of Construction Engineering and Management, 133(1), 10-21. https://doi.org/10.1061/(ASCE)0733-9364(2007)133:1(10)

[2] Kim, K., Walewski, J., \& Cho, Y. K. (2016). Multiobjective construction schedule optimization using modified niched pareto genetic algorithm. Journal of Management in Engineering, 32(2), 1-12. https://doi.org/10.1061/(ASCE)ME.1943-5479.0000374

[3] Dmitriev, A. N., Vladimirova, I. L., Kallaur, G. Y., \& Tsygankova, A. A. (2019). Approaches to classifying building innovations while implementing information 
modeling and project management. Journal of Engineering Science and Technology Review, 12(2), 143-151.

https://doi.org/10.25103/jestr.122.20

[4] Janekova, J., Fabianova, J., \& Fabian, M. (2019). Assessment of Economic Efficiency and Risk of the Project Using Simulation. International Journal of Simulation Modelling, 18(2), 242-253. https://doi.org/10.2507/IJSIMM18(2) 470

[5] Khaled, E. \& Amr, K. (2005). Time-cost-quality trade-off analysis for highway construction. Journal of Construction Engineering and Management, 131(4), 477-486. https://doi.org/10.1061/(ASCE)0733-9364(2005)131:4(477)

[6] Dho, H. J. \& Khaled, E. (2011). Multi-objective optimization of resource leveling and allocation during construction scheduling. Journal of Construction Engineering and Management, 37(12), 1080-1088. https://doi.org/10.1061/41020(339)82

[7] Gholamreza, H. \& Shiva, F. (2014). Group decision making for stochastic optimization of time, cost, and quality in construction projects. Journal of Computing in Civil Engineering, 28(2), 275-283. https://doi.org/10.1061/(ASCE)CP.1943-5487.0000264

[8] Ayman, A. A. H., Souma, M. A. A., Ghaleb, J. S., \& Rateb, J. S. (2010). Statistical analysis on the cost and duration of public building projects. Journal of Management in Engineering, 26(2), 105-112. https://doi.org/10.1061/(asce)0742-597x(2010)26:2(105)

[9] Xiang, Y. (2003). Fuzzy comprehensive optimization of construction time-cost trade-off. China Civil Engineering Journal, 36(3), 46-50. https://doi.org/10.1007/s11769-003-0044-1

[10] Dorokhov, O., Chernov, V., Dorokhova, L., \& Streimkis, J. (2018). Multi-criteria choice of alternatives under fuzzy information. Transformations in Business \& Economics, 17(2), 95-106.

[11] Mckim, R., Hegazy, T., \& Attalla, M. (2000). Project performance control in reconstruction projects. Journal of Construction Engineering and Management, 17(4), 137-141. https://doi.org/10.1061/(ASCE)0733-9364(2000)126:2(137)

[12] Zhang, L. Y., Du, J. J., \& Zhang, S. S. (2014). Solution to the time-cost-quality trade-off problem in construction projects based on immune genetic particle swarm optimization. Journal of Management in Engineering, 30(2), 163-172. https://doi.org/10.1061/(ASCE)ME.1943-5479.0000189

[13] Soares, R. M., Pinto, J. C., \& Secchi, A. R. (2016). An optimal control-based safety system for cost efficient risk management of chemical processes. Computers and Chemical Engineering, 91, 471-484. https://doi.org/10.1016/j.compchemeng.2016.04.029

[14] Koo, C., Hong, T., \& Kim, T. (2015). An integrated multiobjective optimization model for solving the construction time-cost trade-off problem. Journal of Civil Engineering and Management, 21(3), 323-333. https://doi.org/10.3846/13923730.2013.802733

[15] Monghasemi, S., Nikoo, M. R., Fasaee, M. A. K., \& Adamowski, J. (2015). A novel multi criteria decision making model for optimizing time-cost-quality trade-off problems in construction projects. Expert Systems with Applications, 42(6), 3089-3104. https://doi.org/10.1016/j.eswa.2014.11.032

[16] Moumen, M. \& El Aoufir, H. (2017). Quality, safety and environment management systems (QSE): analysis of empirical studies on integrated management systems (IMS). Journal of Decision Systems, 26(3), 207-228. https://doi.org/10.1080/12460125.2017.1305648

[17] Islam, M. S., Nepal, M. P., Skitmore, M. \& Kabir, G. (2019). A knowledge-based expert system to assess power plant project cost overrun risks. Expert Systems with Applications, 136, 12-32.

https://doi.org/10.1016/j.eswa.2019.06.030
[18] Farahnaz, R. P. \& Kaveh, K. D. (2017). A new stochastic time-cost-quality trade-off project scheduling problem considering multiple-execution modes, preemption, and generalized precedence relations. Industrial Engineering \& Management Systems an International Journal, 16(3), 271-287. https://doi.org/10.7232/iems.2017.16.3.271

[19] Zalmai, L. M., Akcay, C., \& Manisali, E. (2019). Time-cost optimization using harmony search algorithm in construction projects. Revista de la Construccion, 18(2), 226-237. https://doi.org/10.7764/RDLC.18.2.226

[20] Ahn, H., Kim, H., \& Choi, H. L. (2018). Integrated risk management method development for multiple aerospace projects using a single index expression. International Journal of Aeronautical and Space Sciences, 19(3), 1052-1062. https://doi.org/10.1007/s42405-018-0092-5

[21] Togan, V. \& Eirgash, M. A. (2019). Time-cost tradeoff optimization of construction projects using teaching learning based optimization. KSCE Journal of Civil Engineering, 23(1), 10-20. https://doi.org/10.1007/s12205-018-1670-6

[22] Adolfo, C. S. (2019). Quality and safety of the nurse practice environment: Implications for management commitment to a culture of safety. Nursing Forum, 54(4), 537-544. https://doi.org/10.1111/nuf.12367

[23] Beatriz, M. S., Nicoletta, G. C., \& Francisco, S. F. (2018). Artificial intelligence model to analyze sustainability management of maritime ports. DYNA, 93(1), 67-74. https://doi.org/10.6036/8508

[24] Li, H. B., Xiong, L., \& Liu, Y. B. (2015). A literature survey of project resource leveling. Control \&Decision, 30(5), 769779. https://doi.org/10.13195/j.kzyjc.2014.1330

[25] Shen, J. H., Liu, L. D., Sun, X. N., \& Zhang, X. R. (2017). Project duration-cost optimization based on improved harmony search algorithm. Journal of Engineering Management, 31(2), 121-125. https://doi.org/10.13991/j.cnki.jem.2017.02.024

[26] Zhuo, J. S. \& Lu, H. M. (2017). Research on multi-objective optimization of engineering projects based on particle swarm optimization. Journal of Engineering Management, 31(6), 101-106. https://doi.org/10.13991/j.cnki.jem.2017.06.019

[27] Bettemir, O. H. \& Sonmez, R. (2015). Hybrid genetic algorithm with simulated annealing for resource-constrained project scheduling. Journal of Management in Engineering, 31(5), 1-8. https://doi.org/10.1061/(ASCE)ME.1943-5479.0000323

[28] Adeli, A. \& Broumandnia, A. (2018). Image steganalysis using improved particle swarm optimization based on feature selection. Applied Intelligence, 48(6), 1609-1622. https://doi.org/10.1007/s10489-017-0989-x

\section{Contact information}

Yancang LI, PhD, Professor

School of Water Conservancy and Hydroelectric Power Hebei University of Engineering,

No. 19, Taiji Road, Handan, Hebei Province, 056038, China

E-mail: liyancang@hebeu.edu.cn

Shuren WANG, PhD, Professor

(Corresponding author)

International Joint Research Laboratory of Henan Province for Underground Space Development and Disaster Prevention, Henan Polytechnic University, No. 2001 Century Avenue, Jiaozuo, Henan Province, 454003, China E-mail: w_sr88@163.com

Yongsheng HE, MD, Senior Engineer Institute of National Defence Engineering, Academy of Military Sciences, No. 3 Xishan Road, Luoyang, Henan Province, 471023, China E-mail: 704132755@qq.com 